\title{
Emotional Management in the Workplace of the Spanish Population. Quantitative Analysis through the Construction of an Emotional Quality Index at Work and its Link to Social Structure
}

\author{
María Cascales Mira \\ UNIVERSIDAD DE SEVILLA \\ mcascales@uus.es \\ ORCID. 0000-0002-1535-5424
}

Received: 09/04/2019

Accepted: 24/06/2020

\begin{abstract}
The organisation of work, located in the post-Fordist paradigm, stresses the emotional aspects of employee-client interaction processes. This emphasis arises from the shift in the productive structure towards growth in service activities in which interpersonal relationships are key factors. In this "new culture", the organisation is conceived as a 'sentient' environment and emotional work captures the interest of researchers and social scientists who analyse the role played by emotions in occupations and organisational culture (Zapf, 2002, Grandey 2000, 2015, Seymour and Sandiford 2005, Bolton 2000, Wharton, 2009, Totterdell, and Holman, 2003). Most related research has focused on qualitative case studies of workers in the service sector (Steinberg and Figart, 1999) - an approach that limits the inferences one can make and hinders one in linking findings to the social structure. The aim of our research is to expand this field of analysis and explore the link between emotional management and social structure. That is why we used a quantitative methodology, for which purpose we built an Emotional Quality Index in the Workplace (EQIW), allowing us to measure the emotional quality of workers in Spain and analyse their relationship with the three key structural variables: social class; occupation; gender. Here, we used data from the European Working Conditions Survey (2015). The results show that there are significant differences in the emotional management of work by occupation, social class and gender, verifying that there is indeed a link between the EQIW and the social structure.
\end{abstract}

Keywords: Emotional Management, Emotional Quality Index at Work, Structural Factors, Social Class.

Corresponding author: María Cascales Mira. Universidad de Sevilla. Facultad de Ciencias de la Educación. Calle Pirotecnia, 19, 41013 Sevilla (Spain).

Suggested citation: Cascales Mira, M. (2021). Emotional Management in the Workplace of the Spanish Population. Quantitative Analysis through the Construction of an Emotional Quality Index at Work and its Link to Social Structure. Debats. Journal on Culture, Power and Society, 6, 43-54. DOI: http://doi.org/10.28939/iam.debats-en.2021-3 


\section{INTRODUCTION. EMOTIONAL WORK IN THE NEW SPIRIT OF CAPITALISM}

Over the past two decades, emotion has been put on the organisational agenda (Bolton and Boyd 2003), with researchers and social scientists showing growing interest in the subject (Zapf, 2002, Grandey 2000, 2015; Seymour and Sandiford 2005; Bolton 2000; Wharton, 2009; Totterdell, and Holman, 2003). The reason for this lies in the major shift towards service industries found in advanced societies and the rise in jobs where interpersonal relationships play a key role in the way organisations work. The shift from manufacturing to service industries has driven new dynamics in labour relations, with emotions at the core of corporate culture. This culture rests on a "new spirit of Capitalism", which introduces creative and emotional dimensions as key factors for managing organisations, and has become enshrined in the new managerial ideology since the 1990s (Boltanski and Chiapello, 2002). The emergence of this new spirit is related to the paradigm shift in labour relations. This shift was from the Fordist model (which saw corporations as heartless, rational settings where workers followed scientifically-set routines) to the post-Fordist model. In the latter, the creative, emotional part of work is vindicated, contrasting with the rigidities of the mass-production model of yore. Now, it is argued that "Organisations have feelings" (Albrow, 1994) and have become flexible settings where interaction with others is a key competitive factor. As Bolton points out: "In direct contrast to the orthodox view of rational bureaucracy, we are now presented with emotional organisations and it is increasingly accepted that emotion constitutes a major element of the "new' organisation of the 1990s" (Bolton, 2000: 158). Although the emergence of emotion in corporations does not spell the end of reason, emotion and rationality have become intertwined. There are two reasons for this. The first is that "corporate culture" requires workers to become more emotionally involved with clients. The second is that "financial logic" increasingly permeates the "new" management team (Bolton, 2000: 159). Here, Hochschild (1983) argued that a distinctive feature of contemporary societies is executives' growing interest in incorporating emo- tions as a way to drive performance and to manage companies (D’Oliveira, 2018: 114).

Coinciding with the emergence of this "new spirit of Capitalism", social scientists began to analyse the role emotions play at work and in organisational culture, the emotional content of many kinds of job, and the social and personal consequences of emotional management at work (Clay-Warner and Robinson, 2008; Hochschild, 1979, 1983; Wharton, 2009; Grandey, 2000; Sennett and Cobb 1972; Gorroño 2008). Research on emotional management in corporations often takes the form of qualitative case studies on workers in the service sector (Steinberg and Figart, 1999). This kind of research has several limitations. Sampling is one of these given that the number of workers surveyed tends to be fairly small and unrepresentative, with studies often focusing on a small subset of workplaces or even just one (Wharton, 2009). This makes it well-nigh impossible to make inferences and to link findings with the broader social structure. Our research has two goals with a view to remedying these shortcomings. The first goal is to measure the quality of emotional work among Spanish workers by employing a quantitative methodology. To this end, we construct an 'Emotional Quality Index at Work' (EQIW). The methodology lets us measure the diverse aspects implied by the complex, multidimensional concept of 'emotional work'. We used data from the Eurofound European Working Conditions Survey 2015 to operationalise the index given that it: (a) incorporates a set of key indicators bearing on emotional management at work; (b) has a wide sample base, enabling us to link emotional work with the social structure. The second goal is to analyse the link between emotional quality of work and social structure, through three variables. There is a pattern of affective experiences based on social structures (Hochschild, 1975), since members of the various segments of society experience and manage emotions based on the place they occupy in the social pecking order (Shott, 1979).

The paper's scheme is as follows: the first part reviews the literature on emotional work. The second part 
describes the EQIW model and its structural variables. The third part sets out the operationalisation of the model is explained. The fourth part describes the analyses and findings, and gives the main conclusions.

\section{EMOTIONAL WORK AS PART OF ORGANISATIONAL DYNAMICS}

The post-Fordist paradigm of work organisation stresses the emotional aspects of employee-client, employee-boss, and employee-employee interactions for control purposes. This control not only covers quantitative aspects of staff performance but also workers' ability to incorporate emotional management in their jobs (Hochschild, 1983). Companies are increasingly seeking to manage workers' emotions (repressing, hiding, or eliciting specific ones, as the case may be) in order to secure competitive advantages (Bolton and Boyd 2003) in a setting where "The Customer is King" (Alonso and Fernandez, 2013: 55).

'Emotional labour' was a term coined in the 1980s by Arlie Hochschild, who explicitly introduced the concept in his book The Managed Heart: Commercialization of Human Feeling (1983). In this seminal work, Hochschild studied the labour dynamics in the burgeoning Tertiary Sector. The book added the concept to existing physical and cognitive factors to take account of the new demands made by the service sector (D'Oliveira, 2018). Following in Hochschild's footsteps, many studies have been carried out that use the concept of emotional labour to analyse: (a) how organisations seek to manage employee's emotions as part of the work process (Ashforth and Humphrey, 1993; Morris and Feldman, 1996; Bolton and Boyd, 2003; Bolton, 2000; Grandey, 2000; Zapf, 2002; Wharton, 2009), and (b) the impact of emotional factors in the workplace (Bericat, 2001; Gorroño, 2008; Bolton, 2006; Calderón, 2008; Steinberg and Figart, 1999).

What is meant by emotional labour? Based on Hochschild's definition, it consists of the management of worker's feelings to create the appearance of accord with the organisational rules, and to generate a desired response in others. "I use the term emotional work to refer to the management of feeling to create a publicly observable facial and body presentation; emotional work is sold for a salary and therefore has exchange value" (Hochschild, 1983: 7). Emotional work involves social interaction within the framework of rules that dictate how to act emotionally. As D'Oliveira points out "when emotional work is done, individuals elaborate their emotions according to certain rules of feeling in a specific field of interaction" (D'Oliveira, 2018: 112). The worker's presentation of an adequate emotional image responds to the organisation's visualisation rules (Hochschild, 1983; Grandey, 2000; Wharton 2009; Morris and Feldman, 1996; Ashforth and Humphrey, 1993), which may be explicitly established or known through observation of co-workers (Grandey, 2000). The rules are designed to make the worker feel an emotion that is not initially present (evocation) while suppressing an existing one (suppression), or modelling an emotion (Hochschild, 1979). The rules of emotional action have received several names: display rules (Ekman, 1973) (when it comes to which emotions should be expressed publicly but not necessarily felt); feeling rules (Hochschild 1979, 1983) (when the rules specify the range, intensity, duration and object of the emotion to be 'felt'). From a dramaturgical standpoint Hochschild (1983) established two main ways in which actors handle emotions: (i) through surface acting, where emotional expressions are regulated; (ii) through deep acting, where feelings are consciously modified to express the desired emotion. According to the author, service sector workers need to do more emotional work in their daily jobs with a view to evoking responses in others that boost corporate profits ${ }^{\mathbf{1}}$. Wages are increasingly tied to workers' ability to perform in these ways.

1 'Pecuniary' emotions follow commercially-inspired rules, although Bolton distinguishes three more kinds of emotions that are not inspired by mercenary considerations, namely: 'professional pride', presentational skills, and philanthropic feelings, all of which follow the rules found in social emotions (see Bolton 2000, 2005, 2009) 
Managing emotions for a salary is termed emotional labour (Hochschild, 1983) since it occurs in a commercial context and has exchange value in the market. $^{2}$ In this context, emotional management is carried out as part of the work activity, it is exchanged for a salary and its purpose is to generate a profit or capital gain for the organisation. Thus it becomes part of the public sphere in the supply of services in which emotional performance adds 'exchange value' and enshrines a business approach (Hochschild, 1983). Thus, the commercialisation of feelings becomes a vital part of the Capitalist labour process in service societies (Hochschild, 1979, 1983), framing the economic changes that took place at the end of the $20^{\text {th }}$ Century. The result of this paradigm shift is a ruthless commercialisation of emotional life (Hochschild, 2008). According to D’Oliveira, "Hochschild's analysis affects precisely some of these transformations in contemporary Western societies. Among them are the emergence of a "new" or more developed Capitalism; the growth of the services sector [...] changes in work dynamics; the growing participation of women in public life, and so forth" (D’Oliveira, 2018: 113).

These transformations in the work organisation model since the end of the 20th Century have shaped a "new spirit of Capitalism" in which the emotional dimension has become the key to grasping corporate culture in the service sector. Within this framework, Hochschild's research has performed an invaluable role in placing emotional management in a broader context by linking "the work of emotions, the rules of feelings and the social structure" (Hochschild, 1979: 276). In this connection, our research analyses the link between emotional work and social structure. The following sections describe the emotional work construct and its operationalisation through the Emotional Quality Index at Work (EQIW), and

2 The concept of 'exchange value' is a key component in emotional work and its roots lie in Marxist theory. Hochschild uses the Marxist distinction between 'use value' and 'exchange value' to refer to emotional work as a good that is exchanged for a wage (D'Oliveira, 2018) set out the key structural variables. We then go on to analyse the link between the index and social structure through its relationship to occupation, social class and gender.

\section{MODEL COMPOSITION. INDEX OF EMOTIONAL QUALITY AT} WORK, AND STRUCTURAL VARIABLES.

In setting up the empirical model to measure emotional work we have taken into account the following aspects. First of all, the concept of emotional work adopted in this paper focuses on the observable behaviours of emotion management based on visualisation rules (Wharton, 2009), not on workers' deeply internalised actions. Following Ashforth and Humphrey (1993), we prefer to use the concept of display rules rather than feeling rules, since what interests us is the external expression of emotions required of workers by the organisation. Second, we focus on the emotional aspects of employeeclient interaction as a key dimension in the context of services, leaving aside employee-employee and supervisor-employee interactions. Following Zapf (2002) we use 'client' to refer to anyone who interacts with an employee, for example, patients, students, customers, passengers, guests and so forth. Along these lines, we treat emotional work with reference to the quality of interactions between employees and clients (Zapf, 2002).

How has emotional work been measured? Few studies have operationalised emotional work with a single measure since it is a complex concept encompassing several dimensions. That is why a multi-dimensional approach is a better yardstick as it lets one specify the various features of emotional work (Wharton 2009). Research treating the subject as a multi-dimensional concept has measured it through various indicators such as: the frequency and duration of interactions; the variety of emotions required; the discrepancy between expressed and felt emotion; compliance with visualisation rules; interactive work measures (Morris and Feldman, 1996; Hochschild, 1983; Wharton 1993, 2009; Rafaeli and Sutton, 1989; Erikson and 
Ritter 2001; Steinberg, R. and Figart, D 1999). More recent studies have used a variety of strategies to identify and measure key factors. Although there is no consensus on the best approach, Wharton (2009) has highlighted practical measures containing some common elements, namely: job interaction requirements, workers' efforts in managing emotions, and display rules and compliance therewith. Given the diversity of aspects encompassed by emotional work and the complexities of measuring it, we discarded a uni-dimensional approach in favour of a multidimensional one based on a composite index. "An index or composite indicator is a complex descriptive structure, based on a theoretical framework and a conceptual definition, which forms an empirically operationalisable measurement model capable of quantifying a social aspect or phenomenon" (Bericat and Sánchez, 2015: 3). In accordance with the dimensions proposed by Wharton (2009), we have operationalised the concept through the construction of an Emotional Quality Index based on three parameters: (1) Interaction; (2) Visualisation of Emotions; (3) Workers' Efforts in Managing Emotion.

1. Interaction: There is broad agreement that occupations requiring emotional work are those in which workers must interact with others. Accordingly, researchers have used indicators such as the frequency and type of these interactions as a way of measuring emotional work. The management of emotions seems to be a characteristic of "almost all occupations in which the worker must interact with people" (Wharton, 2009: 158). In our analysis we have used interaction to measure emotional work through the following indicator:

"Please tell me, using the following scale, the extent to which your main job requires you to work with angry clients, students, patients, etc.?" The 7-point scale's scheme is: $1=$ All the time; 2 = Most of the time; 3 = About three-quarters of the time; $4=$ Half the time; $5=$ About a quarter of the time; $6=$ Almost never; $7=$ Never.
2. Visualisation of Emotions: One way to capture the degree to which workers manage emotions at work is by asking them about the visualisation of emotions, either in the form of expression or suppression. In this analysis, the indicator covers the extent to which emotions have to be hidden at work, corresponding to Hochschild's concept (1983) of suppression. Here, an unwanted emotion or feeling is deliberately suppressed so that the desired image can be put over to the client. The indicator used to measure this suppression is the following variable:

"For each of the following statements, select the answer that best describes your work situation: Your job requires you to hide your feelings." The 5-point scale's scheme is: $1=$ Always; $2=$ Most of the time; 3 = Sometimes; 4 = Rarely; 5 = Never)

3.Workers' Effort in Managing Emotions: This dimension reflects the extent to which employees have to manage their emotions at work in situations they may find disturbing, and seek to differentiate the management of emotions from the interactive work itself. Based on Hochschild, several researchers have designed measures in which workers engage in superficial or deep action when carrying out their activity (see Grandey 2003). The indicator that we have used to measure the effort in managing emotions is:

"Please tell me, using the following scale, the extent to which your main job involves being in emotionally disturbing situations." The 7-point scale's scheme is: $1=$ All the time; 2 = Most of the time; $3=$ About three-quarters of the time, $4=$ Half the time; $5=$ About a quarter of the time; $6=$ Almost never; $7=$ Never .

We have operationalised the concept through an Emotional Quality at Work Index (EQIW) through the foregoing parameters and their corresponding indicators. We shall now go on to describe the structural variables of social class, occupation and gender. 


\section{Structural variables: Social Class (EGP), Occupation (ISCO) and Gender}

According to some authors (Grandey, 2000; Wharton, 2011; D’Oliveira 2018, among others) Emotional Management at Work's vital contribution lies in the link it forges between emotion and social structure (Hochschild 1979, 1983). In emotional work, people actively shape and direct their feelings but the social structure and institutions impose restrictions. In this sense, emotions are not seen in their biological dimension but rather as responses to a societally-configured normative structure (Hochschild, 1979, 1983; Kemper, 1987; Bolton 2008; Shott, 1979; Bericat, 2000). That is why it is so important to analyse the relationship between emotional work and the structural factors shaping emotional quality in the job.

To analyse the relationship between EQIW and social class, we constructed the 'EGP' variable, named after Erikson, Goldthorpe and Portocarero's class typology (1979). This variable is based on a neo-Weberian scheme that distinguishes between two elements: (1) possession or not of the means of production; (2) the nature of the relationship with the employer (Breen, 2005). The typology is expressed in Roman numerals and is as follows. Classes I and II represent the service class par excellence, Class I is large owners with employees and Class II is professionals. Class III is non-routine manual workers (Class IIIa is clerks, Class IIIb is assistants, shop and other lower-grade sales services), Class IV is the petty bourgeoisie (comprising: Class IVa is small owners with employees; Class IVb is small owners without employees; Class IVc is small agricultural owners), Class V is technicians and supervisors, Class VI is skilled workers and Class VII is unskilled workers (Class VIIa is industrial workers, Class VIIb is agricultural labourers).

To analyse the relationship between EQIW and occupation, we used the International Standard Classification of Occupations (ISCO-88), which is based on the International Labor Organization's scheme (ILO) for organising job and employment information. ${ }^{3}$ The survey gathers information on occupations through the ISCO-88 variable. Jobs are classified into the following categories: Armed Forces; Managers; Professionals; Technicians and Associated Professionals; Administrative Support Workers; Sales and Service Workers; Specialised Workers in Agriculture; Forestry and Fishing; Crafts and Related Trades; Plant and Machine Operators; assembly workers and basic occupations. Gender analysis has been a focus of interest in research on emotional labour. Hochschild (1983) highlighted that most service jobs are performed by women, and as such, gender becomes an important aspect in analysing emotional work. The growth of service-related activities (which require greater employee-client interaction and thus more emotional work) has spawned a market niche in which women occupy most of the jobs. This has led to what some authors call the 'feminisation' of the service sector (Hertel, 2017; Wharton, 2009). Wharton and Erickson (1993) also agree that women are more likely to manage emotions both at work and at home and thus tend to be more involved in situations requiring emotional management.

\section{OPERATIONALISATION OF THE MODEL}

This section covers the construction of the EQIW empirical model used for verifying the adequacy through statistical analysis. ${ }^{4}$ Factorial Analysis (a multivariate statistical technique for analysing interdependence relationships among a set of variables) was employed for this purpose. The idea behind Factorial Analysis is to come up with a small number of factors that can represent the original variables, identifying explanations for the correlations between those variables. It is used to reduce and summarise the data being analysed into a meaningful structure. The most suitable method for factor extraction is

3 The classification scale is a tool for organising jobs in a set of clearly-defined groups depending on the tasks and functions carried out in each kind of work.

4 The statistical analysis was carried out through SPSS (Statistical Package for the Social Sciences). 
Principal Components Analysis (PCA). Employing this, we obtained a factor (which includes all the proposed indicators) that explains $59.6 \%$ of the variance, with a $\mathrm{KMO}^{5}$ (Kaiser-Meyer-Olkin Test) figure of 0.62 . The factorial scores were high (above 0.60 ) therefore all the model's indicators represent the factor well.

In the descriptive analysis one needs to ensure the internal reliability of the data. For this purpose we used Cronbach's Alpha, which is a measure of internal consistency - that is, how closely related a set of items are as a group. It estimates the lower bound of the reliability coefficient based on the average of the correlations between the items. The reliability measure using Cronbach's Alpha assumes that the items (measured on a Likert-type scale) measure the same construct and are highly correlated. The alpha score was $0.657^{6}$, which indicates that the indicators are well correlated. Finally, the index was operationalised such that a higher score represented greater emotional management and a lower score, less emotional management.

The following table shows the results of the factor scores. The result of the iterations led to the calculation of a factor making up the Emotional Quality Index at Work. The indicators yielded high scores for the factor (above 0.6), which means that they represent it well. These results show that the index is suitable for measuring emotional labour. Earlier studies showed that work content factors such as control must be taken into account, which has been a good predictor of well-being since it leads to less staff burn-out (Erickson and Wharton 1997: Erikson and Ritter, 2001)

5 The KMO provides information on the extent to which the simple fits the hypothesis of the Factorial Analysis model.

6 Huth, De Lorme and Reid (2006) the reliability value in an exploratory study must be equal to or greater than 0.6 ; in confirmatory studies, it must lie between 0.7 and 0.8 .
Table 1 Factor scores in the EQIW

\begin{tabular}{|l|c|}
\hline EWCS variables (2015) & Component \\
\hline $\begin{array}{l}\text { Does your main job require you to } \\
\text { work with angry clients, students, } \\
\text { patients, etc.? }\end{array}$ & 0.804 \\
\hline $\begin{array}{l}\text { Does your main job put you in } \\
\text { situations that are emotionally } \\
\text { disturbing? }\end{array}$ & 0.830 \\
\hline $\begin{array}{l}\text { Does your job require you to hide } \\
\text { your emotions? }\end{array}$ & 0.673 \\
\hline
\end{tabular}

Source: EWCS (2015)

\section{Indicator frequencies}

Once we had verified the indicators (i.e. that they adequately measure the concept of emotional labour), we drew up a frequency table for 2015 and compared the results for 2010 and 2015 to see whether there had been any change in the demands made by emotional work over the five-year period. Table 2 shows the frequencies of the three indicators used in the index. Looking at the accumulated percentages of "Always" and "Almost always" it will be seen that: $29.4 \%$ of workers dealt with angry clients as part of their jobs; $30.4 \%$ had to hide their feelings; $18 \%$ faced situations that they found emotionally disturbing.

The following table shows the cumulative frequencies in "Always" and "Almost always" categories for the indicators in 2010 and in $2015 .{ }^{7}$ The data reveals a rise in the emotional demands placed on workers over the 5 -year period, with $25 \%$ of workers stating in 2010 that they had to hide their feelings at work, a figure that rose to $30.4 \%$ in 2015 . Regarding working with angry clients, $12.6 \%$ of workers always or almost always worked with angry clients in 2010, a figure that rocketed to $29.4 \%$ in 2015 .

7 The 'emotionally disturbing situations' variable could not be included given that this indicator was not used in the 2010 survey. 
Table 2 Frequency of EQIW indicators for 2015 (in percentages)

\begin{tabular}{|l|c|c|c|}
\hline & $\begin{array}{c}\text { Dealing with angry } \\
\text { clients }\end{array}$ & Hide emotions & $\begin{array}{c}\text { Emotionally disturbing } \\
\text { situations }\end{array}$ \\
\hline Always & 11.2 & 15.8 & 4.2 \\
\hline Almost always & 18.2 & 14.6 & 13.8 \\
\hline Sometimes & 9.2 & 21.9 & 8.1 \\
\hline Rarely & 30.0 & 12.9 & 28.6 \\
\hline Never & 31.3 & 34.8 & 45.3 \\
\hline
\end{tabular}

In short, there was a rise in emotional labour demands over the five-year period. Workers had to make greater emotional management efforts in their jobs and suppress unwanted emotions/feelings in order to create the image desired by their employers. Three out of ten workers had to deal with angry clients. The data reveal the importance of emotional work and the role of emotional management in labour relations. This relevance is increasingly reflected in surveys on working conditions as they incorporate and measure these new facets. For instance, the 6th European Working Conditions Survey had an item measuring emotional demands as a component of the workload, along with the usual intellectual, physical and psychological demands of the job. The survey data revealed that $21.5 \%$ of the workers stated they that they "Always or Almost always" had to cope with emotional demands (the percentage was similar to that covering intellectual demands) and that $15.6 \%$ "Often" had to deal with emotional demands (in this case, a percentage higher than that for intellectual demands). These data indicate that the present level of emotional demands

Table 3 Cumulative figures for "Always" and "Almost always" in the EQIW indicators for 2010 and 2015 (in percentages)

\begin{tabular}{|c|c|c|}
\hline & Hide feelings & $\begin{array}{c}\text { Deal with angry } \\
\text { clients }\end{array}$ \\
\hline 2015 & 30.4 & 29.4 \\
\hline 2010 & 25.1 & 12.6 \\
\hline
\end{tabular}

Source: EWCS 2010 and 2015 roughly equalled that for intellectual demands (Marrero and Abdul-Jalbar, 2015). This finding stresses the need to take emotional demands into account when gauging job quality.

Link between the Emotional Quality Index at Work and social class, occupation and gender.

Applying the EQIW on a database with a large sample size $(3,200$ cases for Spain) and with a great variety of occupations, collected through the ISCO international code of occupations gave us some advantages in coming up with a much more representative sample than that found in qualitative studies. In the latter case, such studies use relatively small samples drawn from a single workplace or from a small subset of workplaces (Wharton, 2009) .Using these conditions we measured the link between the EQIW and three structural factors: social class; occupation; gender. Table 4 shows the average index score by social class and gender. The data reveal that the social classes that are most strongly linked to interaction and interpersonal relationships are the ones that score the lowest in the index (i.e. their emotional quality at work is lower). By comparison, the social classes most strongly linked to the industrial and agricultural sector score highest in the index. Entrepreneurs with employees (I), professionals (II), and low-grade routine white-collar workers (IIIb) (corresponding to lower-grade assistants, office workers, stores and other sales services) were the social classes most likely to deal with angry clients, to hide their feelings, to suffer the most stress, and to find themselves emotionally disturbing work situations. 
Table 4 EQIW by social class (EGP) and gender

\begin{tabular}{|l|c|}
\hline EGP & EQIW \\
\hline I & -0.3374788 \\
\hline II & -0.3070742 \\
\hline IIla & -0.0655459 \\
\hline IIIb & -0.2830549 \\
\hline IVab & -0.0108619 \\
\hline IVc & 0.6680796 \\
\hline V+VI & 0.415297 \\
\hline VIla & 0.3059678 \\
\hline VIIb & 0.5703623 \\
\hline & \\
\hline Género & \\
\hline Male & 0.07999 \\
\hline Female & -0.08303 \\
\hline
\end{tabular}

Source: EWCS 2015

Given the logic underlying the theoretical framework of the post-industrial model, women take a greater part in the service sector and therefore undertake more emotional labour. In our analysis, the average score of the emotional quality index at work for women was negative (indicating that they have a lower quality of emotional management than men). Earlier studies revealed that women are exposed to greater emotional labour in the post-industrial model (Hochschild, 1979, 1983; Wharton, 2009; Wharton and Erikson, 1993), which has been accompanied by a marked feminisation of service occupations (Esping-Andersen 1993, 1999; Hertel, 2017).

Table 5 shows the mean index score by occupations, with those requiring interaction with others and in the service sector associated with lower job quality when it comes to emotional management at work.

Professionals are those with the worst average score of all occupations (-0.324), followed by service and sales workers (-0.246). These are jobs where workers had to deal with angry clients, patients, students, etc. and
Table 5 EQIW by ISCO-88 occupation

\begin{tabular}{|l|c|}
\hline ISCO & EQIW \\
\hline Managers & -0.17789 \\
\hline Professionals & -0.32431 \\
\hline $\begin{array}{l}\text { Technicians and associated } \\
\text { professionals }\end{array}$ & -0.18442 \\
\hline Workers and administrative support & -0.15180 \\
\hline Service and sales workers & -0.24620 \\
\hline $\begin{array}{l}\text { Specialised agricultural, forestry, and } \\
\text { fishing workers }\end{array}$ & 0.51259 \\
\hline Craftsmen and related jobs & 0.35069 \\
\hline $\begin{array}{l}\text { Plant and machine operators, } \\
\text { assembly workers }\end{array}$ & 0.31199 \\
\hline Basic occupations & 0.32000 \\
\hline The Armed Forces & 0.08952 \\
\hline
\end{tabular}

that spawn emotionally-disturbing situations. These workers hide their feelings to a greater extent than those in other occupations given that a key part of their work involves face-to-face interactions. Managers, associate professionals and technicians, and administrative support workers also showed negative scores on this index. The occupations scoring highest were those in the agricultural sector (workers specialised in agriculture, forestry and fishing), with the highest scores for emotional quality at work (0.5125), followed by artisans and unskilled workers (machine operators and basic jobs).

In general terms, there were differences in emotional quality at work depending on social class, occupation and gender. To check whether the differences were statistically significant, we performed a one-way ANOVA (ANalysis Of VAriance) to compare several groups with a quantitative dependent variable, which in this case was the EQIW. The category variables (nominal or ordinal) defining the groups that sought to compare covered social class and occupations, constituting the 
independent or factor variables. ${ }^{8}$ The hypothesis tested in the one-way ANOVA was that the population means (the means of the dependent variable, the EQIW, at each level of the independent variables) were equal. Assuming $k$ independent populations, the contrast hypotheses were as follows:

$\mathrm{H}_{0}: \mu 1=\mu 2=\ldots=\mu \mathrm{k}$ The population means are equal

H1: $\mu 1 \neq \mu 2=\ldots=\mu \mathrm{k}$ At least two population means are different

The goal was to check whether the EQIW impact varies depending on social class and occupation (Alternative Hypothesis, H1) or on the contrary its impact is not affected by these factors (Null Hypothesis, $\mathrm{H}_{0}$ ).

In the ANOVA performed for each of the independent variables and the EQIW, the p-value was $<0.00$, so we must reject the null hypothesis of equality of means. The conclusion we drew from the hypotheses tests is that social class and occupation significantly affect the index score. In other words, the emotional quality of work is influenced by structural variables.

\section{CONCLUSIONS}

Given: (a) the growing importance of service sector activities; (b) the paradigm shift towards post-Fordist organisational models based on interpersonal work; (c) rising emotional demands at work, one needs to focus attention on a new dimension of labour (namely, the

8 We were unable to include gender in this analysis given that it was not present in over two response categories. quality of emotional management at work). Surveys are beginning to address this need as they increasingly incorporate items on both emotional demands in jobs and the key aspects of emotional work. This paper makes two major contributions to this field of research. The first is the construction of an index measuring the quality of emotional management at work based on three parameters: (a) Interaction; (b) Visualisation of Emotions; (c) Workers' Effort spent on Emotion Management. The second is by establishing a link between emotional work and key structural factors such as social class, occupation and gender.

The main findings of our study are that: (1) the index constructed to measure emotional quality at work was both empirically valid and verified; (2) the link between emotional quality at work and structural variables was verified. Classes I, II and IIIb (workers who are more exposed to dealing with clients and interpersonal work) scored worse for emotional job quality than manual and agricultural workers. There were also differences by occupation, with professionals, and service and sales workers having the worst emotional quality at work, followed by managers, technicians and associated professionals and administrative support staff. Last but not least, we found differences by gender, with women suffering worse emotional quality at work than men - a finding mirroring that in earlier studies (Hochschild, 1979, 1983; Wharton and Erikson, 1993; Wharton, 2009). These results invite new research on the importance of emotional management for work quality. This is because differences stemming from structural variables may be a new facet of structural inequality when it comes to emotional quality at work in post-industrial societies.

\section{BIBLIOGRAPHIC REFERENCES}

Albrow, M. (1994). “Accounting for organizational feeling”. Universidad de Sevilla in L. Ray and M. Reed (ed.), New Weberian perspectives on work, organization and society. London: Routledge.

Alonso, L.E. and Fernández, C.J. (2013). Los discursos del management: Una perspectiva crítica. Lan Harremanak, 28(I), 42-69. 
Ashforth, B. E. and Humphrey, R. H. (1993). Emotional labor in service roles: The influence of identity. Academy of Management Review, 18(1), 88-115.

Bericat, E. (2000). La sociología de la emoción y la emoción en la sociología. Papers, 62,145-176.

Bericat, E. (2001).Max Weber o el enigma emocional del origen del capitalismo. Reis, 1(95)

Bericat, E. (2016). The sociology of emotions: Four decades of progress. Current Sociology, 64(3), 491-513.

Bericat, E. and Sánchez, E. (2015). Structural gender equality in Europe and its evolution over the first decade of the twenty first century. Social Indicators Research, 127(1).

Boltanski, L. and Chiapello, E. (2002). El nuevo espíritu del capitalismo. Madrid: Ediciones Akal.

Bolton, S (2000). Emotion here, emotion there, emotional organizations everywhere. Critical Perspectives on Accounting, 11, 155-171.

Bolton, S. (2006). Una tipología de la emoción en el lugar de trabajo. Sociología del Trabajo, 57, 3-30.

Bolton, S. and Boyd, C. (2003). Trolley dolly or skilled emotion manager? Moving on from Hochschild's managed heart. Work, Employment and Society, 17(2), 289-308.

Breen, R. (2005). Foundations of neo-Weberian class analysis. In E. O. Wright, Approaches to Class Analysis (p. 3150). New York: Cambridge University Press.

Calderón, J. (2008). Trabajo, subjetividad y cambio social: rastreando el trabajo emocional de las teleoperadoras. Cuadernos de Relaciones Laborales, 26(2), 91-119

Clay-Warner, J. and Robinson, D.T. (2008). Social structure and emotion. San Diego: Academic Press.

D’Oliveira, M. (2018). Arlie Russell Hochschild: Un camino hacia el corazón de la sociología. Madrid: Centro de Investigaciones Sociológicas.

Ekman, P. (1973). Cross-cultural studies of facial expression: A century of research in review. New York: Academic Press.

Erikson, R., Goldthorpe J. and Portocarero, L. (1979). Intergenerational class mobility in three Western European societies: England, France and Sweden. The British Journal of Sociology.Special Issue. Current Research on Social Stratification, 30(4), 415-441.

Erickson, R. J. and Ritter, C. (2001). Emotional labor, burnout, and inauthenticity: Does gender matter? Social Psychology Quarterly, 64(2),146-163.

Esping-Andersen, G. (1993). Changing classes: Social stratification in postindustrial Europe and North America. London: Sage.

Esping-Andersen, G. (1999). The social foundations of postindustrial economies. Oxford: Oxford University Press.

Eurofound (2010). Fifth European Working Conditions survey. Luxemburg: Publications Office of the EU. https:// www.eurofound.europa.eu/surveys/european-working-conditions-surveys/fifth-european-working-conditionssurvey-2010

Eurofound (2015). Sixth European Working Conditions Survey. Luxemburg: Publications Office of the EU.https:// www.eurofound.europa.eu/surveys/european-working-conditions-surveys/sixth-european-working-conditionssurvey-2015

Gorroño, I. (2008). El abordaje de las emociones en las organizaciones: Luces y sombras. Cuadernos de Relaciones Laborales, 26(2).

Grandey, A. (2000). Emotion regulation in the workplace: A new way to conceptualize emotional labor. Journal of Occupational Health Psychology, 5(1), 95-110.

Grandey, A. (2003). When "the show must go on": Surface acting and deep acting as determinants of emotional exhaustion and peer-rated service delivery. AMJ, 46, 86-96.

Grandey, A. (2015). Smiling for a wage: What emotional labor reaches us about emotion regulation. Psychological Inquiry, 26, 54-60.

Hertel, F. R. (2017).Social mobility in the 20th century:Class mobility and occupational change in The United States and Germany. Wiesbaden: Springer.

Hochschild, A. R. (1979). Emotion work, feeling rules, and social structure. American Journal of Sociology, 55(3), 551-575.

Hochschild, A. R. (1983). The managed heart: Commercialization of human feeling. Berkeley: University of California Press.

Hochschild, A. R. (2008). La mercantilización de la vida íntima: Apuntes de la casa y el trabajo (translation Lilia Mosconi). Barcelona: Katz Ediciones. 
Huth, J., De Lorme, D. E. and Reid, L. N. (2006). Perceived third-person effects and consumer attitudes on prevetting and banning DTC advesiting. Journal of Consumer Affairs, 40(1), 90-116.

National Institute of Safety and Hygiene at Work (2007). VI Encuesta Nacional de Condiciones de Trabajo (ENCT). Madrid: Ministerio de Trabajo e Inmigración. https://www.insst.es/documents/94886/96082/ VI+Encuesta+Nacional+de+Condiciones+de+Trabajo.pdf/be86e34c-c6f4-49ac-9ebf-a042637fbea7?t=1522935836000

Kemper, T. (1987). How many emotions are there? Wedding the social and the autonomic components. American Journal of Sociology, 93(2), 263-289.

Marrero, J. R. and Abdul-Jalbar, B. (2015). Las exigencias emocionales en el trabajo: El caso español. Papers, 100(2).

Morris, J. A. and Feldman, D. C. (1996). The dimensions, antecedents, and consequences of emotional labor. Academy of Management Review, 21(4), 986-1010.

Orzechowicz, D. (2008). Privileged emotion managers: The case of actors. Sociology Psychology Quarterly, 1(2), $143-56$.

Rafaeli, A. and Sutton, R.I. (1989). The expression of emotion in organizational life. Research in Organizational Behavior, 11,1-42.

Sennett, R. and Cobb, J. (1972). The hidden injuries of class. Cambridge: Cambridge University Press.

Seymour, D. and Sandiford, P. (2005). Learning emotion rules in service organizations: Socialization and training in the UK public-house sector. Work, Employment and Society, 19(3), 547-564.

Shott, S. (1979). Emotion and social life: A symbolic interactionist analysis. American Journal of Sociology, 84(6), 1317-1334.

Steinberg, R. J and Figart, D. M. (1999). Emotional demands at work: A job content analysis. Annals of the American Academy of Political and Social Science, 561, 177-191.

Totterdell, P. and Holman, D. (2003). Emotion regulation in customer service roles: Testing a model of emotional labor. Journal of Occupational Health Psychology, 8(1), 55-73.

Wharton, A. S. (1993). The affective consequences of service work: Managing emotions on the job. Work and Occupations, 20(2), 205-232.

Wharton, A. S. (2009). The sociology of emotional labor. Annual Review of Sociology 35, 147-165.

Wharton, A. S. (2011). The sociology of Arlie Hochschild. Work and Occupations, 38(4), 459-464.

Wharton, A. S. and Erickson, R. J. (1993). Managing emotions on the job and at home: Understanding the consequences of multiple emotional roles. Academy of Management Review, 18(3), 457-486.

Zapf, D. (2002). Emotion work and psychological well-being: A review of the literature and some conceptual considerations. Human Resource Management Review, 12, 237-268.

\section{BIOGRAPHICAL NOTE}

\section{María Cascales}

She holds a PhD in Sociology from the University of Seville and has been working there as an interim professor in the Department of Sociology since 2010. Her field of research is in the Sociology of Work and the Sociology of Emotions, linked to the social structure. Her latest publications have been La calidad intrínseca del trabajo y su vinculación con las lógicas laborales [The Intrinsic Quality of Work and its Link to Labour Policies] (2021) in Revista Española de Sociología, and New Model for Measuring Job Quality: Developing an European Intrinsic Job Quality Index (2021) in the journal Social Indicators Research. She is a member of the Studies on the Quality of European Societies (ECALSE) and took part in the publication of the book The Quality of European Societies: A Compilation of Composite Indicators, writing the chapter "Job Quality" (Springer, 2019). Cascales has participated in the INCASI network (International Network for Comparative Analysis of Social Inequalities), funded by the European Commission, through which she has spent several research stays in Latin America. She is currently taking part in the research project "Dynamics of Social Mobility in Spain" (DINAMOS), which is linked to the aforementioned INCASI project.

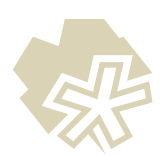

